\title{
ICT OPPORTUNITIES AND CHALLENGES FOR REMOTE SERVICES
}

\author{
Jouni Pyötsiä \\ Metso Automation, Tulppatie 7 A, PO Box 310 , \\ 00811 Helsinki, Finland \\ jouni.pyotsia@metso.com
}

Abstract: Embedded intelligence together with upcoming ICT solutions give new possibilities for more automated service process operation over network during the life cycle of machines and systems. The purpose of this paper is to describe the existing solution based on Web Services and how it can be enhanced utilizing semantic web approach.

First, the paper describes automation and ICT challenges from business and technology point of view. Next, the paper presents a remote and networked service solution based on a business hub approach. The solution consists of service provider's Central Hub and several customers' Site Hubs, which have been integrated together over network. Finally, the benefits and future challenges of the new solution and semantic web utilization and approach are discussed.

Key words: Information technology, Intelligent machines, Embedded systems, Maintenance, Life cycles technology

\section{INTRODUCTION}

Rapid changes and discontinuities in the $21 \mathrm{st}$ century business environment will challenge companies. To ensure high flexibility, sustainable growth and profitability companies have to find new innovative business solutions. In many cases technology as such is not anymore sufficient to ensure competitive edge. New innovative business solutions 
call for strong integration of automation technology, information and communication technology (ICT) and business processes.

Especially the close integration requirements are true in new emerging remote and networked service solutions. Embedded intelligence in different machines and systems gives new possibilities for more automated business process operation over network during the machines and systems life cycle.

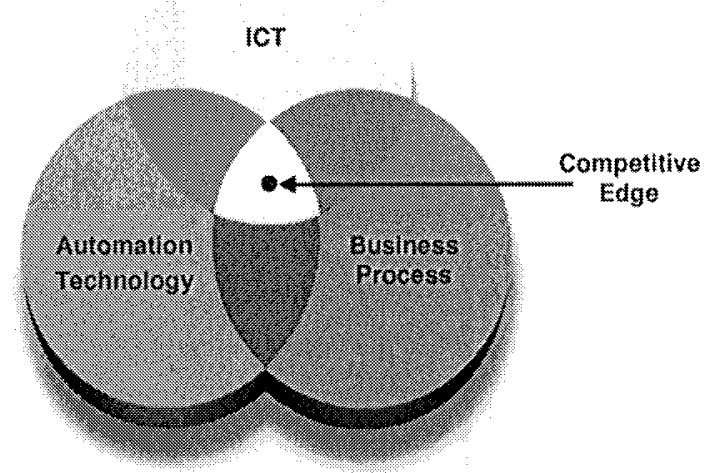

Figure 1. Ensuring competitive edge in future solutions means more close integration of different technologies and business processes.

The new emerging remote service solutions demand that products are transforming into life cycle services and these services are transforming into customers' service processes. Business messages coming from intelligent machines and systems drive these processes utilizing embedded intelligence and ICT solutions.

In the future the different collaborative resources like intelligent machines, systems and experts create huge amount of new data and information during the machines and systems life cycles. This information and message flow management and compression to on-line knowledge is also a demanding challenge.

On the other hand, optimization requirements demand more effective knowledge utilization and speed up network-based learning during the collaboration between different resources.

To overcome these demands we have to utilize Web Services, new upcoming semantic web based solutions and intelligent agent approach. 


\section{METSO'S STRATEGY AND ICT /1/}

Metso Corporation is a global supplier of process industry machinery and systems as well as know-how and aftermarket services. The Corporation's core businesses are fiber and paper technology, rock and minerals processing and automation and control technology.

Metso's strategy is based on an in-depth knowledge of its customers' core processes, the close integration of automation and ICT, and a large installed base of machines and equipment.

Metso's goal is to transform into a long-term partner for customers. Metso will develop solutions and services to improve the efficiency, usability and quality of customers' production processes through their entire life cycles.

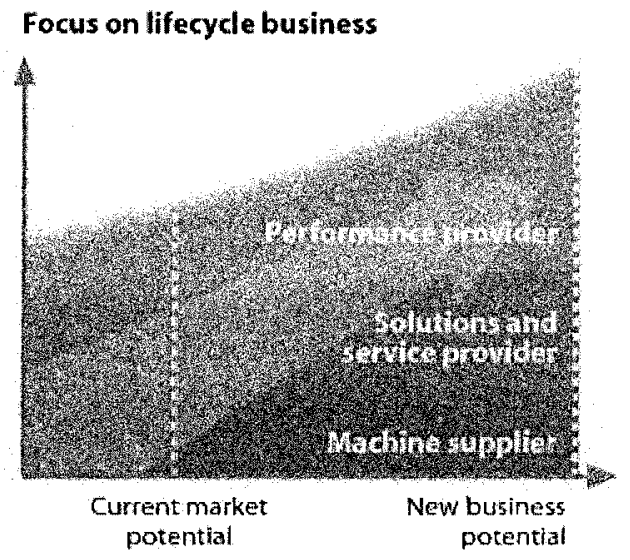

Figure 2. Metso's large installed base of machines and equipment creates a firm foundation for transformation into after market services.

Close co-operation between the customer makes it possible to optimize entire processes utilizing more embedded intelligence. Already in the design phase remote service capabilities can be embedded into machines and processes, which, in turn, form the basis for remote monitoring, process optimization and optimal maintenance and service solutions. Process optimization saves energy, raw materials and costs, minimizes emissions and environmental impacts and extends process life cycles.

ICT opens up the new possibility for remote and networked service business solutions and presents Metso the opportunity to develop new business models. These models must be based on the life cycle business thinking. 


\section{METSO'S ICT CHALLENGES /2/, /4/}

The problems in today's networked business solutions and remote services start from security. Usually business partners have many point-topoint connection holes into their Intranet and have used even modem based connections for that. This usually means low security, difficult management and extra costs for the business partners.

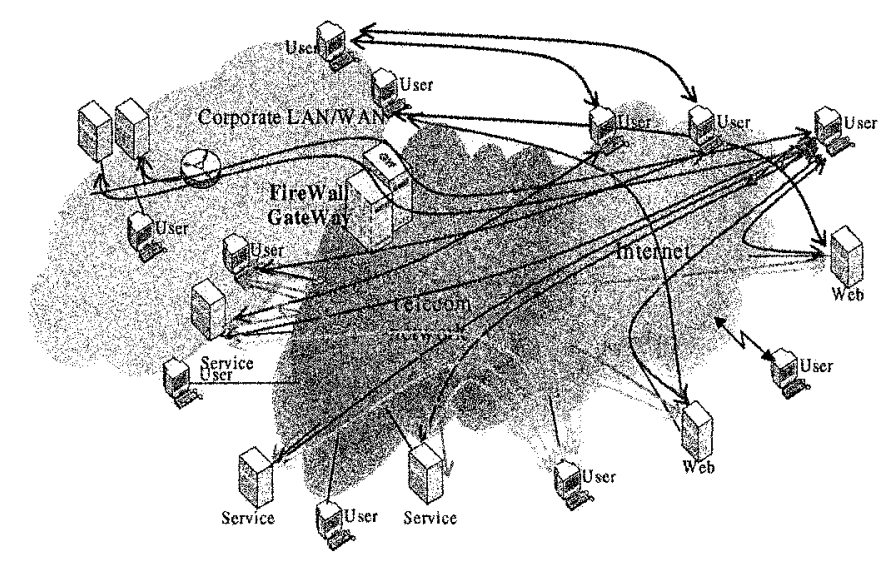

Figure 3. In many cases today connectivity is a real security risk for different partners in networked business environment.

Another problem is the point-to-point integration between different systems and applications. Business process automation, easy integration and business messages management are very difficult inside the company and almost impossible between business partners.

In today's business environment a key driver for a company's business strategy is its adaptation to a changing business environment. ICT must create a flexible and nimble business architecture based on security and cost efficiency to continuously resolve the highest advantage to the business.

From the technology and business point of view the following ICT challenges have to be met to make the required service business transformation a reality:

- Pervasive Communication:

- Machine to machine (m2m)

- Application to application (a2a)

- System to system (s2s)

- Collaboration (b2b)

- Network Security

- High security and confidentiality 
- Easy to build-up and maintain

- Industry Cluster Wide Standards:

- Security

- Messages

- Protocols

- Collaborative business processes

- On-line Customer Services:

- Fast response

- Better focus to real value

- Network based learning

- Operational Excellence:

- Strong cost reduction

- Punctuality in communication

- Fluent business process operation

- Transparency

\section{SOLUTION FOR REMOTE AND NETWORK SERVICES /4/}

\subsection{Business Hub}

Business hub is a solution to provide secure VPN (Virtual Private Networks) connection between Metso and its customers' intelligent machines and systems. Standard and corporate wide security solution creates fast built, reliable and cost effective solution for customers' integration. Strong authentication, strong encryption and traceability of users and connections guarantee high security.

Enterprise Application Integration (EAI) platform is today's solution for collaboration and business logic (rules and process) modeling in the Business hub. Internal integration is always the starting point for more advantaged collaborated solutions. Figure 4 shows Metso's vision 2001 for EAI hub. 


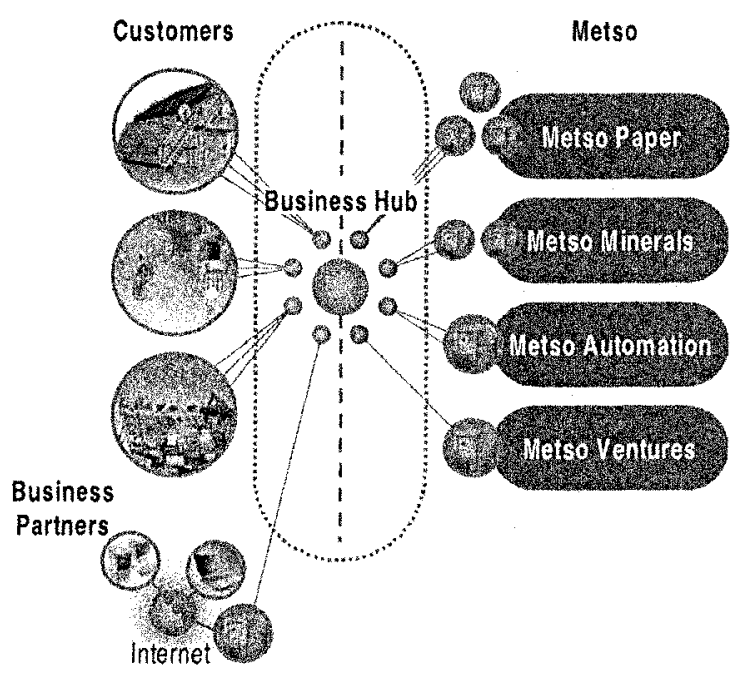

Figure 4. Business hub based on EAI technology is today's solution for collaboration between customers' intelligent machines and systems.

\subsection{Web Services}

Web Services are important building blocks for information exchange (SOAP), description (WSDL) and discovery (UDDI) between different resources (like applications, systems, machines and experts) in global network.

Web Services open up new possibilities to move valuable maintenance and process performance information from customer sites to Metso's Remote Service Centers and experts. The key lies in utilizing the intelligence embedded in installed base and automating the message flows between Metso and its customers' applications through the Internet. Web Services based messages and interfaces will allow machines and systems to communicate with each other independently and automatically over network.

Web Services together with EAI workflow and business process tools create powerful vehicle to automate the operation of remote and networked service solutions. Web Services Flow Language (WSFL) and Business Process Execution Language for Web Services (BPEL4WS) give new possibilities to use open XML based standard for business process and workflow descriptions. 
Figure 5 shows workflow by which it is possible to automate different kinds of functions and operations concerning remote and networked services.

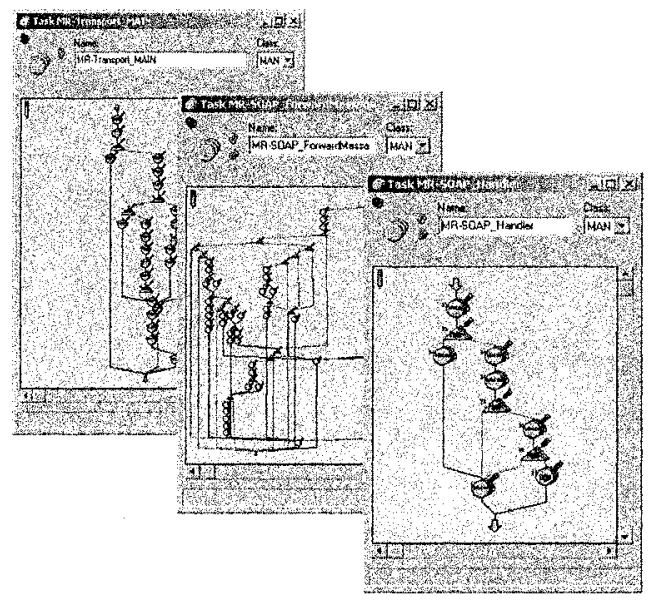

Figure 5. Ready-made "lego" modules by which it is easy and effective to build up service logic and more automated remote and networked service solutions.

\subsection{Remote Service Solution Description}

Metso's remote service solution consists of service provider's Central Hub and several customers' Site Hubs, which have been integrated together over network. SiteHub solution is based on an EAI Platform. In addition to basic EAI functionality the SiteHub includes the following features:

- Message management

- Application management

- User Management

- Message security

- System and application monitoring

- Enterprise wide site hub integration

- Partner network integration

- User interface support

The key issues in SiteHub solution are: open standards, information security, reliability, connectivity and manageability. These requirements are 
met by combining a traditional EAI platform with new features, which are specially designed upon industrial needs.

The factory floor connectivity is one of the main issues with SiteHub solution. While the isolated site operation is well supported, the main power of the information flow comes, when the applications are accessible in office / corporation levels. Open and standard interfaces provide easy access with applications.

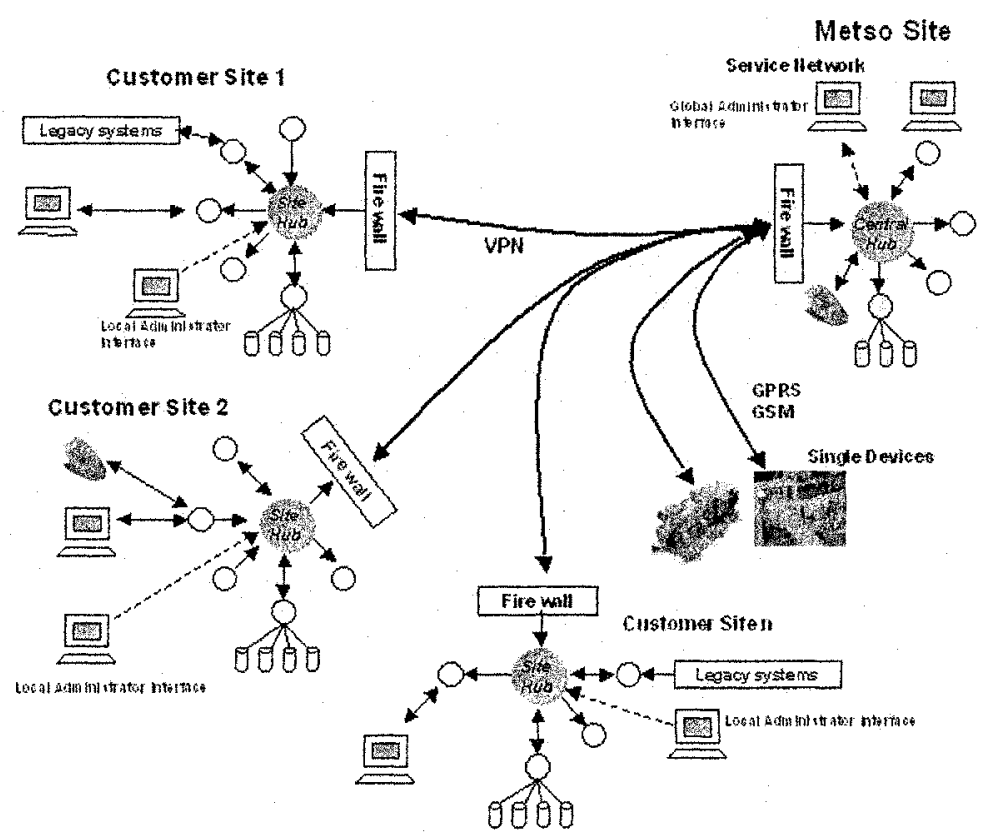

Figure 6. SiteHub network architecture.

\subsection{SiteHub Architecture}

The base building block of the SiteHub is Integration Platform. The operating logic of the hub is implemented as tasks. In addition to these tasks SiteHub consists of two external services: Management service and User Interface service. Management service is handling the management of users and applications connected to the system. User Interface service provides the applications a standard way to present their user interfaces.

Figure 7 presents the architecture and building blocks of the SiteHub solution. 


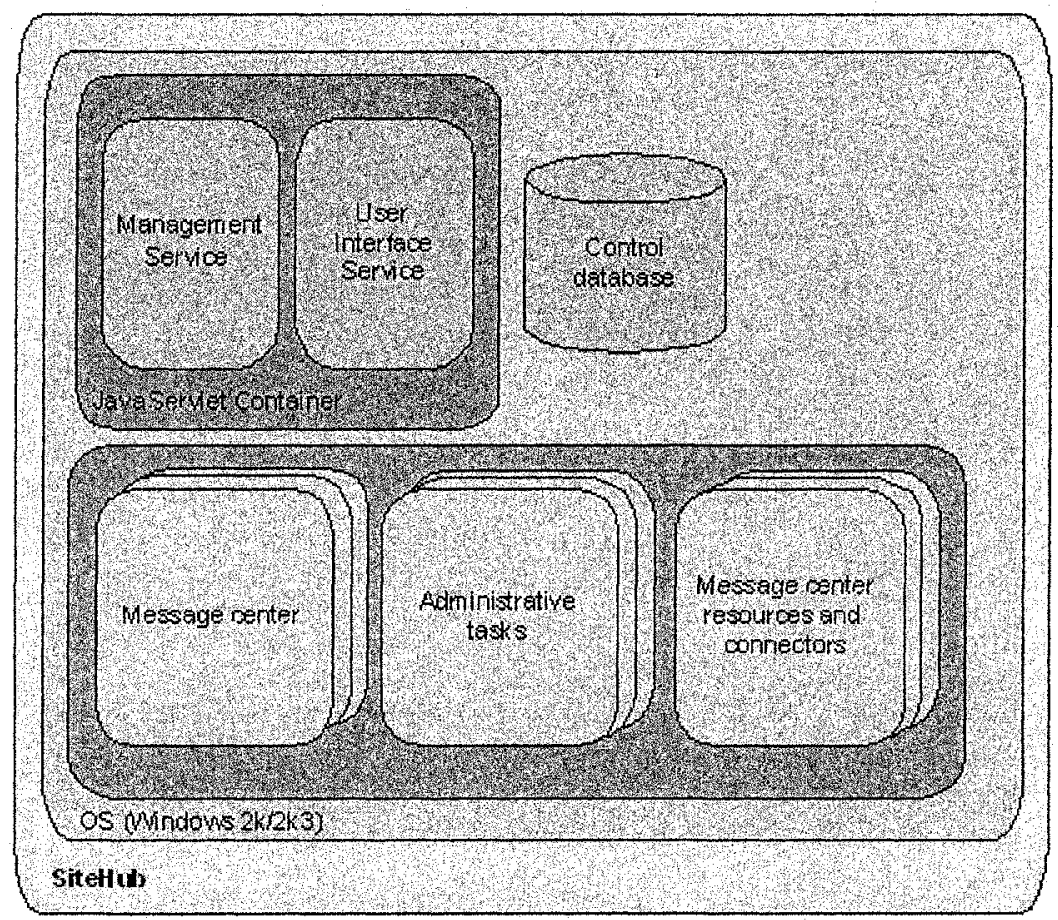

Figure 7. SiteHub architecture.

Message Center in Figure 7 is the main building block of the SiteHub. It takes care of receiving the messages, checking the validity of them and routing them to the correct receivers. Messaging in SiteHub is based on Web Services technology. The operation logic build on top of Integration Platform is working as a message center. It receives the incoming message and delivers the message to the receiving application or to another hub if the receiving application is connected to that.

Message Center supports two message delivery models: synchronous and asynchronous. In synchronous messaging the connection is opened between the sender and the receiver and the receiver has to answer to the message. In asynchronous messaging the Message Center answer to the sender right away it has received the message. In this case the Message Center guarantees that the message is delivered to the receiver. If the receiver cannot be connected the message is stored into the control database. Message Center tries the resending of the message until it can be delivered (or until a specified time has passed). 
Connections from the SiteHub to partners and to Central Hub can be made securely with VPN connections.

\section{FUTURE CHALLENGES $/ 2 /, / 3 /, / 4 /, / 5 /, / 6 /$}

Semantic web technology led by World Wide Web Consortium (W3C) gives totally new opportunities for building information and knowledge management solutions between different resources in networked business environment.

Integration of Web Services and new enabling semantic web technologies (like RDF, RDF(S), OWL and DAML-S) create comprehensive and more intelligent web services environment.

Resource Description Framework (RDF) provides interoperability and easier discovery between different resources that exchange information on the Web. RDF gives good basis for maintenance and performance information description and classification.

Web Ontology Language (OWL) describes the structure of knowledge and enables knowledge sharing and integration between resources. Ontology enhancement for Web Services is the most important remedy for present SiteHub solution.

DARPA Agent Markup Language for Services (DAML-S) describes the upper level ontology for properties and capabilities and it enables automatically discover, invoke, compose and monitor for web services.

With the help of agent technology it is possible to develop a simple and advanced performance evaluation and predictive maintenance concept for intelligent machines and devices. This concept is based on smart agents, a network of smart agents and self-learning capabilities.

The agent-based system determines the performance and health of machines and devices with the help of two indices: performance index and maintenance need index. The performance index is a key to evaluating the operation of machines and devices relating to the operational and control performance. The maintenance index is a key to predicting future needs for maintenance. 


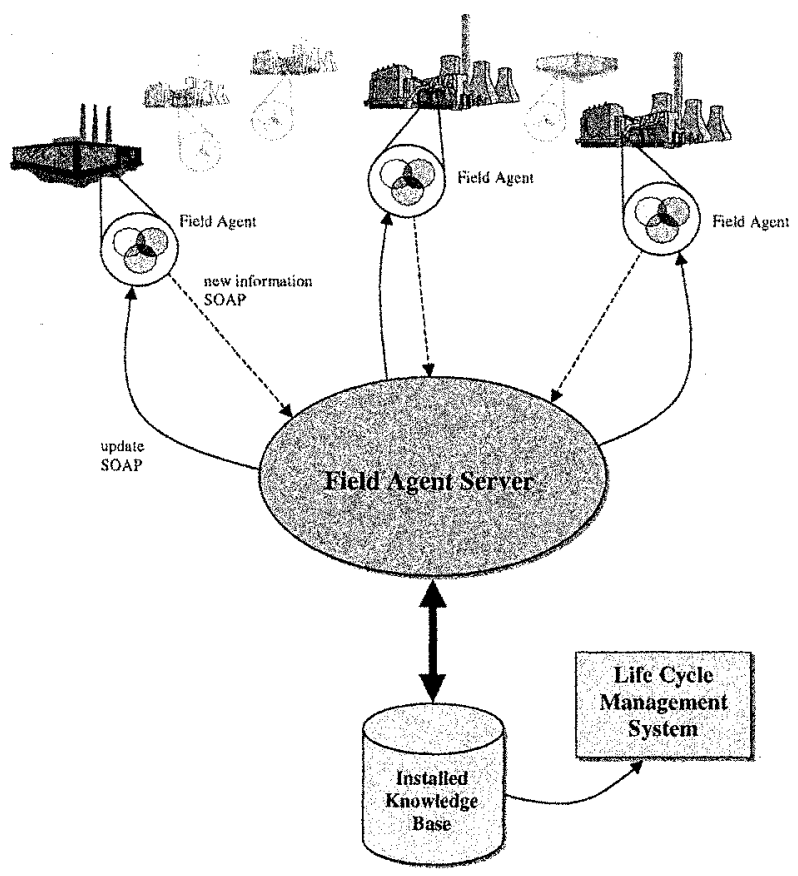

Figure 8. Field Agent network and server architecture.

Field Agent is a software component that automatically follows the performance and health of machines and devices. It is autonomous, it communicates with its environment and other Field Agents, and it is capable of learning new things and delivering new information to other Field Agents. The use of the Field Agent is invisible to the user. It delivers reports and alarms to the user by means of Web Services and new emerging semantic web technologies.

The emerging semantic web technologies give new possibilities also in implementation of Field Agent concept. Semantic Peer-to-Peer (P2P) architecture provides a direct interaction with other Field Agents over network for learning and service discovery.

In emerging remote and networked services the information and knowledge discovery and seamless sharing between different networked resources (applications, systems, intelligent machines and experts) are must. To overcome these challenges semantic web with field agent approach is an important step to more powerful solutions. 


\section{SUMMARY}

It could be said that products and solutions are transforming into services and services are transforming into service business processes in networked business environment.

To make this vision true in remote and networked services we have to closely integrate lots of different kinds of technologies and business processes.

The existing Enterprise Application Integration (EAI) technologies, Web Services and upcoming semantic web technologies give new tools to make valuable integration and ontology description a reality.

New solutions based on the previously mentioned technologies will guarantee the increased yield, decreased total cost of ownership and improved safety through more powerful remote and networked service solutions. The key is that the right information and knowledge are at the right time in the right place in collaborated business environment.

Still a lot of work needs to be done especially in agent-based embedded intelligence and standardization. More capable intelligence is needed into the machines and systems. To create powerful proactive services we have to get more reliable reasoning and even network based learning to support decision making. On the other hand, standards convergence is a must in a more automated business process operation over network. Otherwise lots of adapters, conversions and transformations shall be made to applications, messages and processes between different business partners.

\section{REFERENCES}

/1/ Metso Corporation, Sustainability Report 2003, March 10, 2004, URL: http://www.metso.com

/2/ Pyötsiä J., Cederlöf H., Advanced Diagnostics Concept Using Intelligent Field Agents, ISA99, Philadelphia, USA.

13/ Pyötsiä J., Cederlöf H., Remote Wireless Presence in Field Device Management, ISA EXPO 12-24 August 2000, New Orleans, USA.

14/ Pyötsiä J., New Information and Communication Technology (ICT) Challenges in Remote and Networked Services, IFAC Symposium on Telematics Applications in Automation and Robotics, 21-23 June 2004, Helsinki University of Technology, Finland.

15/ Terziyan V., Kononenko O., Semantic Web Enabled Web Services: State-of-Art and Industrial Challenges In: M. Jeckle and L.-J. Zhang (eds.), Web Services - ICWS-Europe 2003, Lecture Notes in Computer Science, Vol. 2853, Springer-Verlag, 2003, pp. 183-197. 
16/ Terziyan V., Semantic Web Services for Smart Devices Based on Mobile Agents, In: Forth International ICSC Symposium on Engineering Intelligent Systems (EIS-2004), Island of Madeira, Portugal, February 29 March 2, 2004 